\title{
Human immunodeficiency virus/acquired deficiency syndrome (HIV/AIDS): Knowledge and attitude of adolescents towards HIVIAIDS in Kashmir valley
}

\begin{abstract}
The present study was an effort to know the knowledge and attitude towards HIV AIDS among adolescent students of Kashmir valley. HIV/AIDS is a significant threat to humankind and is more alarming to developing countries, where illiteracy and poverty may contribute towards higher risk for HIV/AIDS. It is important that adolescents should have a good knowledge of HIV/AIDS to prevent its spread. The aim of our study was to examine the level of awareness and attitude to HIV/AIDS among students in Kashmir valley. A descriptive study was conducted over a sample of 400 educated adolescents selected at random from various educational institutions of Kashmir valley. The results obtained in our study reveal that $91 \%$ of male students and 93\% female students had heard about HIV/AIDS and students considered HIV/AIDS as a fatal disease. Further, the study reveal that adolescents had adequate knowledge of the basic facts about HIV/AIDS, the transmission of HIV and how they can protect themselves. In order to increase the level of awareness, it is recommended that HIV education should be part of curriculum among all levels of education and religious institutions should play crucial role in preventing HIV/AIDS. Mass media or public media campaign cannot only raise the level of knowledge in adolescents but also in general public of the state.
\end{abstract}

Keywords: HIV/AIDS, Kashmir, adolescents, knowledge, attitude
Volume I Issue I - 2017

\author{
Bilal Ahmad Bhat,' Nusrat, ${ }^{2}$ Humaira Jasmin \\ $\mathrm{Tak}^{3}{ }^{3}$ Tahira Sidiq ${ }^{4}$ \\ 'Department of Social Science, University of SKUAST Kashmir, \\ India \\ ${ }^{2}$ IMFA, University of Kashmir, India \\ ${ }^{3}$ Department of Law, University of Kashmir, India \\ ${ }^{4}$ Department of Home Science, University of Kashmir, India
}

\section{Correspondence: Bilal Ahmad Bhat, Department of Socia Science, University of SKUAST Kashmir, India,}

Email:bhat_bilal@rediffmail.com

Received: April 22, 2017 | Published: May 15, 2017

\section{Introduction}

Human Immune Deficiency Virus/Acquired Immune-Deficiency Syndrome (HIV/AIDS) is the term given to a combination of symptoms which results from a breakdown of the immune system. It is the final stage of HIV infection, which causes severe damage to the immune system and causes fatal infections. AIDS is the second widely spread communicable disease worldwide and the sixth common cause of death globally (WHO, 2004). HIV continues to be a major global public health issue, having claimed more than 39 million lives so far, with 29 million new infections estimated by the near 2020. It is observed that deaths related to HIV/AIDS declined, however the number of new infections is rising. AIDS is caused by a virus called as Human Immune Deficiency Virus (HIV) that attacks the immune system and leaves the body vulnerable to a variety of life-threatening infections and cancers. HIV is transmitted through illegal male female relationships, transfusion of infected blood, use of nonsterile, HIV infected or contaminated syringes and needles and from an infected mother to her unborn child. HIV/AIDS stigma and discrimination exists worldwide, although they manifest themselves differently across countries, communities, religious groups and individuals. Fear of contagion coupled with negative, value-based assumptions about people who are infected leads to high levels of stigma surrounding HIV and AIDS. HIV/AIDS is a life-threatening disease, and therefore people react to it in strong ways. HIV infection is associated with behaviours (such as homosexuality, drug addiction, prostitution or promiscuity) that are already stigmatized in many societies. Most people become infected with HIV through sex, which often carries moral baggage. There is a lot of inaccurate information about how HIV is transmitted, creating irrational behaviour and misperceptions of personal risk. Religious or moral beliefs lead some people to believe that being infected with HIV is the result of moral fault (such as promiscuity or 'deviant sex') that deserves to be punished. There are certain chances of getting ostracized at different places and settings like marriage, place of worship, train, bus, workplace, hostel, hospital and others. HIV/AIDS is one of the biggest challenges faced by India and there are about three million people suffering from HIV/AIDS. It is reported that more than 5000 people were living with HIV virus in the Jammu and Kashmir state. So far 746 people have died in Jammu and Kashmir due to AIDS, while 5018 people are living with 'deadly' HIV virus in the state. In Jammu the number of persons with this deadly disease is more than as is seen in Kashmir ; as around 2649 patients are under treatment at the GMC\&H Jammu including 1520 males, 935 female and 187 children, while in Srinagar around 366 get treatment at SKIMS which includes 280 males, 67 females and 17 children. Socioeconomic condition and poor literacy level are the biggest causes of the spread of the disease throughout the world. Union of India has signed various treaties, agreements and declarations relating to HIV/AIDS, for the protection of rights of those who are HIV positive or most vulnerable to HIV/ AIDS in order to secure their human rights and prevent the spread of HIV/AIDS. The Universal Declaration of Human Rights also lays down that the principle of nondiscrimination is fundamental to human rights law. It equally applies to people suffering from HIV/AIDS. In India there is no comprehensive law to deal with menace of HIV/ AIDS. However, various laws of the constitution guarantees the right of equality to HIV/AIDS patients (Article; 15,16,21,42,47). In India we have also Immoral Trafficking Prevention Act, 1986; HIV/AIDS Bill 2007; HIV/AIDS (Prevention and Control) Bill 2010. In case a person infected with HIV/AIDS is denied treatment or any other 
facility to which a common man is entitled, the aggrieved person can file a petition before the court for his/her readdress. ${ }^{1}$ The researchers in view of the studies like Abdul Bari et al., ${ }^{2}$ Wilson et al., ${ }^{3}$ Zahid, ${ }^{4}$ Shakil, ${ }^{5}$ Campbell, ${ }^{6}$ Boesten, ${ }^{7}$ Nafisa, ${ }^{8}$ Iqbal $^{9}$ chose the present topic in order to know the awareness and precautionary measures taken by students to eliminate HIV/AIDS problem in Kashmir valley.

\section{Material and methods}

A descriptive study was conducted in Kashmir valley of J\&K state based on stratified random sampling procedure. Total sample of 400 adolescents (200 boys and 200 girls) were selected at random from different colleges of Kashmir valley. The level of awareness among adolescents of Kashmir valley about HIV/AIDS was assessed through face to face interview and the answer given to the questions in the well designed simple pretested questionnaire based on the previous studies for the purpose. The data collected was analysed and conclusion was drawn based on appropriate statistical tools.

\section{Results and discussion}

In order to take feedback of the adolescent's awareness about HIV/AIDS, questionnaires were distributed among students and the results obtained are shown in the following tables. As shown in Table 1 that majority of the students about $96.5 \%$ of the male and 93\% of female students had heard about HIV/AIDS, 92\% of male respondents and $88.5 \%$ of female respondents consider HIV/AIDS as a fatal disease, 90.5 male respondents and 89 female respondents considered HIV/AIDS as a communicable disease, $93.5 \%$ of the male respondents and $91.5 \%$ of female respondents agreed that HIV/AIDS infection decreases the immunity, $96 \%$ of the male respondents and $93.5 \%$ of female respondents were of the opinion that HIV/AIDS is diagnosed by blood, $13.5 \%$ of the male respondents and $15.5 \%$ of female respondents were of the view that HIV/AIDS is diagnosed by urine, $95.5 \%$ male students and 96.5 female students were of the opinion that HIV/AIDS be transmitted by having sexual intercourse with HIV/AIDS infected person, $96 \%$ of the male respondents and $92.5 \%$ of female respondents were of the opinion that HIV/AIDS Be transmitted by transfusion of HIV/AIDS infected blood and blood components, $94.5 \%$ male and $93 \%$ female respondents agree that HIV/AIDS be transmitted by sharing syringes/needles with infected person, $76.5 \%$ male and $72.5 \%$ female respondents were of the opinion that HIV/AIDS be transmitted by tattoo making, $91.5 \%$ male and $86.5 \%$ students were of the opinion that HIV/AIDS be transmitted by sharing toilet with infected people, $48.5 \%$ male and $51 \%$ female students agree that HIV/AIDS is transmitted by kissing with infected person, $90.5 \%$ male and $88.5 \%$ female respondents were of the opinion that HIV/AIDS can be transmitted from HIV/AIDS infected mother to child, $19.5 \%$ male and $21.5 \%$ female students were of the opinion that HIV/AIDS can be transmitted by sharing food with HIV/AIDS infected person, $7.5 \%$ male and $8.5 \%$ female students were of the opinion that HIV/AIDS can be transmitted by sneezing or coughing of HIV/AIDS patient, $17.5 \%$ male and $21.5 \%$ female students were of the opinion that HIV/AIDS can be transmitted by shaking hand with HIV infected person, $96 \%$ male and $93.5 \%$ female students were of the opinion that HIV/AIDS can be transmitted by blades used by HIV/ AIDS infected person, 96.5\% male and 95.5\% female students were of the opinion that HIV/AIDS can be transmitted by having multi sex partner at higher risk for contracting HIV/AIDS infections, 91.5\% male and $86.5 \%$ female students were of the opinion that precautionary measures can save a person from HIV/AIDS, $88 \%$ male and $80.5 \%$ female students were of the opinion that imparting sex education to students play an important role in prevention of HIV/AIDS, 71.5\% male and $80.5 \%$ female students were of the opinion that religious institutes play important role in the prevention of HIV/AIDS, $68.5 \%$ male and $74.5 \%$ female students were of the opinion that media can play a vital role in creating awareness about HIV/AIDS among general public, $91.5 \%$ male and $86.5 \%$ female students were of the opinion that parents siblings can play a vital role in the prevention of HIV/AIDS, $88 \%$ male and $83.5 \%$ female students were of the opinion that teachers can play a vital role in the prevention of HIV/ AIDS, $89.5 \%$ male and $92 \%$ female students were of the opinion that friends can play a vital role in prevention of HIV/AIDS. Statistically, it has been observed that there is a non-significant difference in the responses of male and female students $(\mathrm{p}>0.05)$. The results obtained are in agreement with the earlier studies (Abdul Bari ${ }^{2} \&$ Atif et al., ${ }^{10}$ (Table 1)).

Table I Response of adolescent students about HIVIAIDS

\begin{tabular}{|c|c|c|c|c|c|c|c|}
\hline \multirow{2}{*}{ SI. No. } & \multirow{2}{*}{ Question asked } & \multicolumn{2}{|l|}{ Male } & \multicolumn{2}{|l|}{ Female } & \multirow{2}{*}{ Chisquare } & \multirow{2}{*}{ P-value } \\
\hline & & Yes(\%) & No(\%) & Yes(\%) & No & & \\
\hline $\mathrm{I}$. & Have you heard about HIVIAIDS? & $193(96.5)$ & $7(3.5)$ & $186(93)$ & $14(7)$ & 2.463 & $>0.05$ \\
\hline 2. & Is HIVIAIDS a fatal disease? & $184(92)$ & $16(8)$ & $177(88.5)$ & $23+1.5)$ & 1.392 & $>0.05$ \\
\hline 3. & Is HIVIAIDS a communicable disease? & $|8|(90.5)$ & $19(9.5)$ & I78(89) & $22(11)$ & 0.245 & $>0.05$ \\
\hline 5. & Is HIV/AIDS diagnosed by blood? & $192(96)$ & $8(4)$ & $187(93.5)$ & $13(6.5)$ & 1.256 & $>0.05$ \\
\hline 6. & Is HIV/AIDS diagnosed by urine? & $27(13.5)$ & $173(86.5)$ & $3 I(15.5)$ & $169(84.5)$ & 0.323 & $>0.05$ \\
\hline 7. & $\begin{array}{l}\text { Can HIVIAIDS be transmitted by having sexual intercourse } \\
\text { with HIVIAIDS infected person? }\end{array}$ & $191(95.5)$ & $9(4.5)$ & $193(96.5)$ & $7(3.5)$ & 0.260 & $>0.05$ \\
\hline 8. & $\begin{array}{l}\text { Can HIVIAIDS be transmitted by transfusion of HIVIAIDS } \\
\text { infected blood and blood components? }\end{array}$ & $192(96)$ & $8(4)$ & $185(92.5)$ & $15(7.5)$ & 2.260 & $>0.05$ \\
\hline 9. & $\begin{array}{l}\text { Can HIVIAIDS be transmitted by sharing syringes/needles } \\
\text { with infected person? }\end{array}$ & $189(94.5)$ & $\mathrm{II}(5.5)$ & $186(93)$ & $14(7)$ & 0.384 & $>0.05$ \\
\hline 10. & Can HIVIAIDS be transmitted by tattoo making? & $153(76.5)$ & $47(23.5)$ & $145(72.5)$ & $55(27.5)$ & 0.384 & $>0.05$ \\
\hline
\end{tabular}


Table Continued...

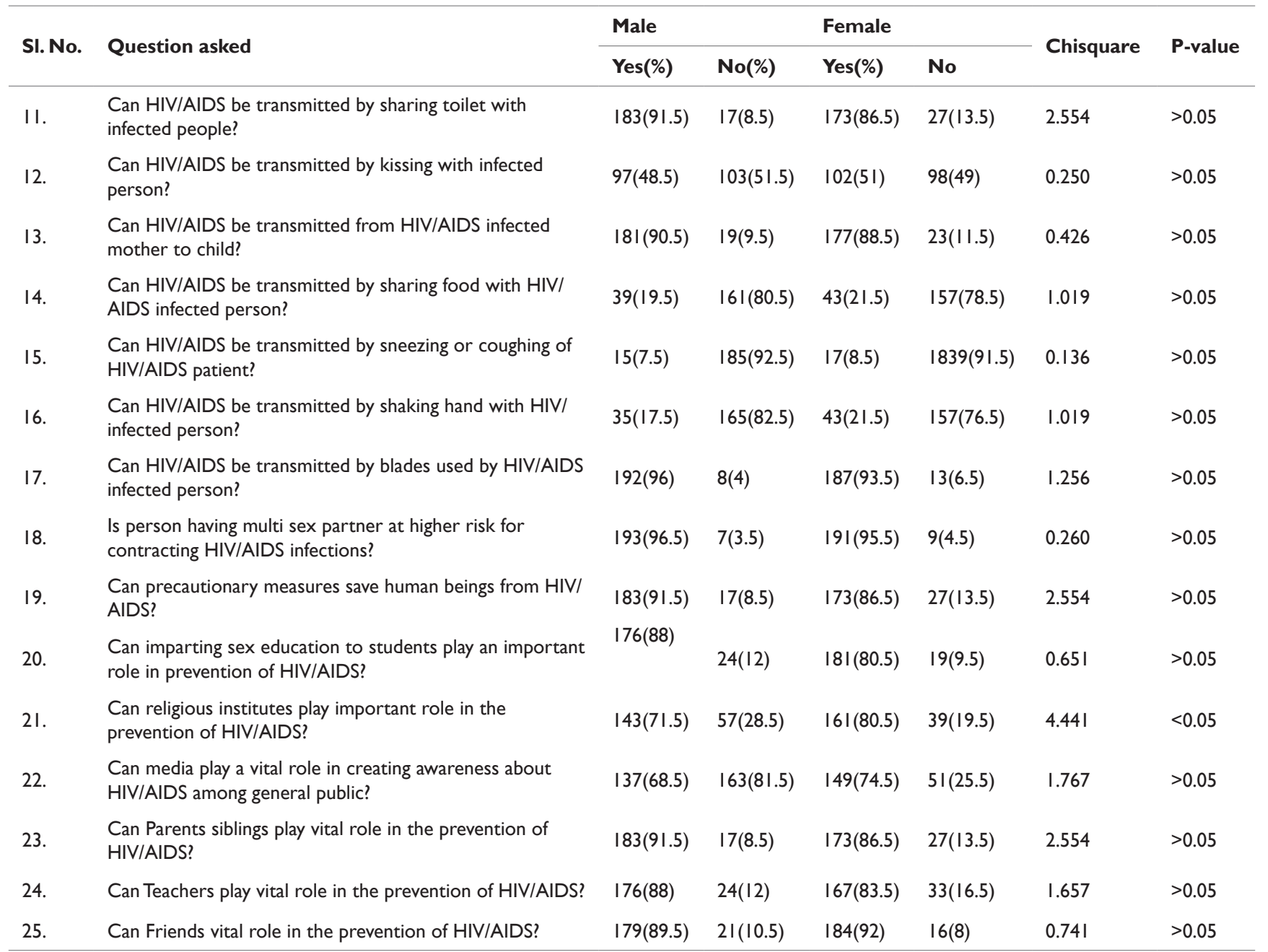

The following tables were designed to check the knowledge of the students about persons which are at high risk for HIV infections. Students were asked whether life style of peoples affects the chances of HIV infection or not. Their response was gathered in "yes" and "no" replies. Information obtained in presented in Table 2. Table 2 shows that $59 \%$ male and $61.5 \%$ female respondents understand

Table 2 Understanding of public high risk life styles unsafe sex, $13.5 \%$ male and $15.5 \%$ female respondents understand drug use; $8 \%$ male and $6 \%$ female respondents understand heroine and other such addictions, $3.5 \%$ male and $2.5 \%$ female respondents understand addiction to pornographic material are the public high risk life styles. The results obtained are in agreement with earlier studies (Atif et al., $+($ Table 2$)$ ).

\begin{tabular}{lllll}
\hline \multirow{2}{*}{ SI. No. } & Factor & Male(\%) & Female(\%) & \multirow{2}{*}{ P-value } \\
\cline { 3 - 4 } & & Yes(\%) & Yes(\%) & \\
\hline I. & Unsafe sex & $118(59)$ & $123(61.5)$ & $>0.05$ \\
2. & Drug use & $27(I 3.5)$ & $31(15.5)$ & $>0.05$ \\
3. & Heroine and other such addictions & $16(8)$ & $12(6)$ & $>0.05$ \\
4. & Addiction to pornographic material & $7(3.5)$ & $5(2.5)$ & $>0.05$ \\
5. & None of the above & $9(4.5)$ & $10(5)$ & $>0.05$ \\
6. & All of the above & $23(I 1.5)$ & $19(9.5)$ & $>0.05$ \\
& Total & 200 & 200 & \\
\hline
\end{tabular}

In order to access the knowledge of students regarding precautionary measures that can prevent the peoples from HIV infections questions as shown in Table 3 were asked. The information obtained reveals that $18 \%$ male, $26 \%$ female respondents believe use of new blades, $27 \%$ male and $21.5 \%$ female respondents believe that transfusion of screened blood, $12 \%$ male and $13.5 \%$ female respondents believe that new and disposal syringe can be the main precautionary measures to prevent HIV infection. The results obtained are in agreement with earlier studies (Atif et al., ${ }^{10}$ (Table 3)). 
Table 3 Precautionary measure against HIVIAIDS

\begin{tabular}{lllll}
\hline \multirow{2}{*}{ S1. No. } & Measures & Male(\%) & Female(\%) & \multirow{2}{*}{ P-value } \\
\cline { 3 - 4 } & & Yes & Yes & \\
\hline I. & Use of new blades & $36(18)$ & $52(26)$ & $>0.05$ \\
2. & Transfusion of screened blood & $54(27)$ & $43(21.5)$ & $>0.05$ \\
3. & New and disposable syringe & $24(12)$ & $27(13.5)$ & $>0.05$ \\
4. & None of the above & $62(31)$ & $59(29.5)$ & $>0.05$ \\
5. & All of the above & $24(12)$ & $19(9.5)$ & $>0.05$ \\
& Total & 200 & 200 & \\
\hline
\end{tabular}

In order to assess the government campaign outcomes regarding educating the peoples about possible causes of HIV/AIDS questions were asked from student. It is observed from Table 4 that $43 \%$ male and $46.5 \%$ respondents got awareness from TV messages about HIV/ AIDS; $22.5 \%$ male and $23.5 \%$ female respondents report that they got awareness of dangerous practices which may lead to HIV/AIDS; $9.5 \%$ male and $7.5 \%$ female respondents believe that they got frightening messages from T.V. and $8.5 \%$ male and $8 \%$ female respondents believe that said the messages have no effect. On the basis of Chisquare test, it is observed that statistically there is a nonsignificant difference between male and female respondents. The results obtained are in agreement with earlier studies (Atif et al., ${ }^{10}$ (Table 4), (Figure1)).

Table 4 Influence of HIVIAIDS TV messages on students

\begin{tabular}{lllll}
\hline \multirow{2}{*}{ SI. No. } & Response & Male(\%) & Female(\%) & P-value \\
\cline { 3 - 5 } & & Yes & Yes & \\
\hline I. & Awareness of HIV/AIDS & $86(43)$ & $93(46.5)$ & $>0.05$ \\
2. & Awareness of dangerous practices which may lead to HIV/AIDS & $45(22.5)$ & $47(23.5)$ & $>0.05$ \\
3. & Messages are frightening & $19(9.5)$ & $15(7.5)$ & $>0.05$ \\
4. & Have no effect & $17(8.5)$ & $16(8)$ & $>0.05$ \\
5. & All of the above & $33(16.5)$ & $29(14.5)$ & $>0.05$ \\
& Total & 200 & 200 & \\
\hline
\end{tabular}

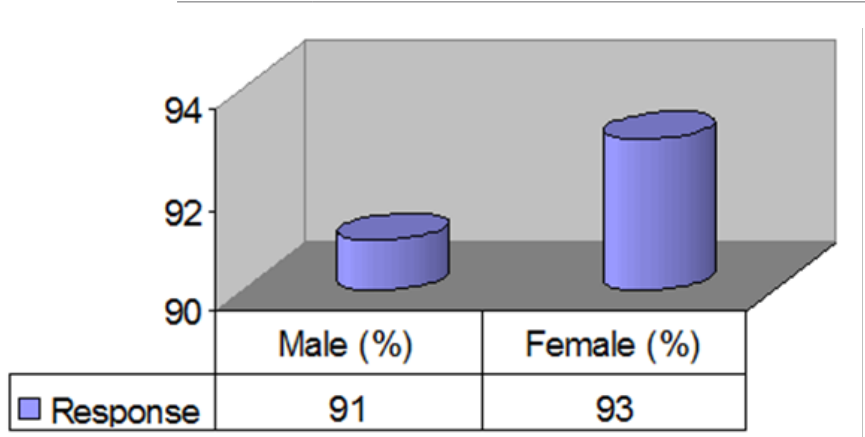

Figure I HIVIAIDS a fatal disease.

The results obtained from our study indicate that carefully planned information, education and communication can be used to correct misunderstandings about HIV/AIDS and HIV/AIDS prevention practices among students in Kashmir valley. Mass media campaigns can raise the bar of knowledge in students of Kashmir Valley. Education is considered as the best line of defence against the spread of the AIDS. There is need to expand and strengthen existing preventive interventions introduced by the government of Jammu and Kashmir. One way of promoting health practices in students is helping them have compassion and understanding of those who are infected, and coping with illness which is appropriate to their level of cognitive development. Our study reveals that $91 \%$ of male and $93 \%$ of female students knew about HIV/AIDS through television and printed media. The awareness through media has a strong impact on the knowledge regarding HIV/AIDS in Kashmir valley. In conclusion, there is a satisfactory awareness among the university students of Kashmir valley. HIV/AIDS is a social disease as well as a medical condition. It has a culminating effect on the social life and society as a whole. HIV/AIDS related Stigma and Discrimination has been as killing as the disease itself and even more than that. In India at many places the HIV positive patients have been forcefully evicted from their homes, their work places, and even some have been denied health care and facilities. HIV positive is considered not less than a devil, off track, mischievous, unfaithful, unclean, unsocial, uncultured, misguided, immoral, and unethical. Stigma and discrimination are an attribute of human instincts, so a man wishes to live a life untouched with disgrace and dishonor. The man's instinctive tendency has made him filter out the dangers that put their survival at risk. This instinctive behaviour leads to stigmatize and discriminate against those we think and perceive as causing danger to not our existence only but to our human stature and attitudinal stance. The study found that above $90 \%$ of the respondents report that conflict, migrant labours, people doing business outside the valley and drivers are the main causes of HIV/AIDS in Kashmir valley. Finally, it is recommended that HIV education should be part of curriculum among all levels of education and religious institutions should play positive role in preventing HIV/ AIDS. ${ }^{11-13}$ 


\section{Acknowledgements}

None.

\section{Conflict of interest}

The author declares no conflict of interest

\section{References}

1. World Health Organization, (2004) World's first health emergency and urgent threat. www.nacp.gov.pk.

2. Abdul Bari Naik, Abdul Raffie Naik, Tanveer Ahmad Lone. Knowledge and attitude regarding HIV/AIDS among college students of Kulgam Jammu and Kashmir. The International Journal of Indian Psychology. 2015;3:2349-3429.

3. Wilson D, Greenspan R, Wilson C. Knowledge about AIDS and Selfreported behaviour among Zimbabwean secondary school pupils. Soc Sci Med. 1989;28(9):957-961.

4. Zahid AK, Laura G, Agha JA, et al. HIV/AIDS and its risk factors in Pakistan. AIDS. 1997;11(7):843-848.

5. Shakil MA. Adolescent's Knowledge about AIDS- Perspective from Islamabad. J Pak Med Assoc. 2001;51(5):194-195.
6. Campbell C. Understanding and challenging HIV/AIDS stigma. University of KwaZulu-Natal, South Africa: Springer; 2005.

7. Boesten J. Gender and HIV/AIDS critical perspectives from the developing world; 2009.

8. Nafisa BT. Frequency of risk factor for transmission of HIV/AIDS Gomal J Med Sci. 2011;9(2):4.

9. Iqbal M. HIV/AIDS and Social Exclusion in Kashmir. The International Journal of Indian Psychology. 2015. p. 1-7

10. Atif Abasi. Human Immunodeficiency virus/Acquired immune deficiency syndrome (HIV/AIDS): Knowledge, attitudes of university students of the State of Azad Kashmir (Pakistan). Journal of AIDS and HIV Research. 2015;5(5):157-162.

11. India Human Development Report 2011:Towards Social Inclusion, Institute of applied manpower research, Planning commission, Government of India, India: Springer; 2011. 257 p.

12. http://www.helplinelaw.com/civil-litigation-and-others/RHPI/rights-ofhivaids-patients-in-india.html

13. Unaids. Global Report 2013; 2013. 